\title{
SOBRE LA DENEGATIO ACTIONIS, EXCEPTIO IURISIURANDO Y LA ACTIO EX IURE IURANDO
}

\author{
Antonio Villanueva Martínez \\ Universidad de Vigo, Espanha \\ avillanueva@uvigo.es
}

RESUMEN: En este artículo analizamos los diversos medios procesales existentes para hacer efectivo el juramento necesario, una vez decidido el litigio por medio de éste. Partiendo de la fuente fundamental D. 12.2.9 pr, estudiamos los supuestos en los que procedía la denegación de la acción y la excepción del juramento, así como la concesión de la actio ex iure iurando. Sostendremos que, en todo caso, los efectos del juramento necesario dependen de su contenido, reconducible a casos típicos.

PALABRAS-CLAVE: Denegatio actionis. Exceptio iurisiurando. Actio ex iure iurando. Juramento necesario. Res iudicata.

On the denegatio actionis, exceptio iurisiurando and the actio ex iure iurando

\begin{abstract}
In this article we analyse the various procedural means available to give effect to the necessary oath, once the dispute has been settled by means of this oath. Starting from the fundamental source D. $12.2 .9 \mathrm{pr}$, we study the cases in which the denial of the action and the exception of the oath, as well as the granting of the actio ex iure iurando, were applicable. We will maintain that, in any case, the effects of the necessary oath depend on its content, which can be extended to typical cases.
\end{abstract}

KEYWORDS: Denegatio actionis. Exceptio iurisiurando. Actio ex iure iurando. Necessary oath. Res iudicata.

Sobre a denegatio actionis, exceptio iurisiurando $e$ a actio ex iure iurando

ABSTRACT: No presente artigo analisamos os diferentes meios processuais existentes para fazer efetivo o juramento necessário, uma vez decidido o litígio por meio deste. Partindo da fonte fundamental D. 12.2.9 pr, estudamos os casos em que ocorriam a negação da ação e a exceção do juramento, assim como a concessão da actio ex iure iurando. Sustentamos que, em todo caso, os efeitos do juramento necessário dependem de seu conteúdo, reconduzível a casos típicos.

KEYWORDS: Denegatio actionis. Exceptio iurisiurando. Actio ex iure iurando. Juramento necessário. Res iudicata.

\section{INTRODUCCIÓN}

Una vez que se presta el juramento necesario ${ }^{1}$, el litigio se da por finalizado y el Pretor ha de defender la posición jurídica de quien haya prestado el juramento. Como quiera que el

1 El criterio de distinción del juramento necesario es su contenido: si éste coincide con la intentio de una actio in ius o la nominatio facti de una actio in factum, se trata de un juramento necesario. En caso de que el contenido del juramento, bien sea una cuestión de hecho o jurídica, no coincide con la intentio o la nominatio facti, el juramento es voluntario. Por otro lado, entendemos que la prestación del juramento necesario exige, como cuestión procedimental, la previa 
contenido del juramento favorece al demandado si éste lo presta ("dare non oportere", "rem suam esse", o fórmulas equivalentes), o al demandante, si es él quien jura ("dare sibi oportere", "rem suam esse" o fórmulas equivalentes), los recursos procesales derivados del juramento necesario son diferentes en ambos casos.

En primer lugar, examinaremos el supuesto de que el demandado jure que no debe dar, o bien que la cosa reivindicada es suya. Después de este juramento, el demandado debe ser defendido ante el demandante por medio de la denegación de la acción a este último, o bien concediéndole una excepción a favor del demandado: abordaremos en qué supuestos el Pretor deniega la acción al demandante y cuando procede una excepción.

Analizada la posición jurídica del demandado que prestó el juramento, hemos de pararnos en las fuentes relativas a los recursos procesales derivados del juramento prestado por el demandante, cuya conclusión podemos adelantar: el demandante será defendido con una acción dimanante del propio hecho de jurar.

\section{JURAMENTO PRESTADO POR EL DEMANDADO: DENEGATIO ACTIO- NIS/EXCEPTIO IURISIURANDI}

El juramento necesario que presta el demandado tendrá como contenido la negativa de que debe dar al demandante ${ }^{2}$, o que la cosa es suya ${ }^{3}$, y ambos contenidos del juramento son decisorios del litigio en la medida en que coinciden con la intentio o la nominatio facti de las acciones dirigidas en su contra, cuyo resultado es, por tanto, desestimatorio de la pretensión del demandante.

Al igual que sucede cuando la pretensión se desestima por medio de sentencia, el demandado debe ser protegido por el Pretor, ya sea denegando al actor una eventual y futura acción, ya sea por medio de la inserción de una exceptio en la fórmula. En caso del juramento necesario, la excepción será la exceptio iurisiurandi, y no la exceptio res iudicata et in iudicium deducta.

El texto que hace referencia de manera más clara a la relación entre ambos medios procesales, esto son, la denegatio actionis y la exceptio, es D. 12.2.9 pr.

\footnotetext{
(Ulpianus libro 22 ad edictum): pr. Nam posteaquam iuratum est, denegatur actio: aut, si controversia erit, id est si ambigitur. An iusiurandum datum sit, exceptioni locus est.
}

Según este pasaje, se deniega la acción después de prestado el juramento. En cambio, si hay dudas de que se haya prestado el juramento, subsistiendo la controversia sobre ese punto,

concesión de la acción y, por tanto, el entablamiento del litigio, produciéndose los efectos ínsitos a la litis contestatio. Por otra parte, sólo cabe prestar el juramento necesario en acciones con intentio certa.

2 V. gr. D. 12.2.26.1 (Paulus libro 18 ad edictum. Si pater filium dare non oportere iuraverit, Cassius respondit et patri et filio dandam exceptionem iurisiurandi: si pater iuraverit in peculio nihil esse, filius conveniri poterit: sed et pater ita convenietur, ut post adquisiti peculii ratio habeatur); D. 12.2.28.8 (Paulus libro 18 ad edictum. Igitur si quis iuravit se non esse condemnatum, etiamsi ex stipulatu iudicatum solvi ob rem iudicatam conveniatur, defendetur per exceptionem. Contra si, cum ex stipulatu iudicatum solvi conveniretur, iuravit se dare non oportere, agenti iudicati non utique obstabit exceptio: potest enim fieri, ut non sit commissa stipulatio, licet res iudicata sit: nisi ideo iurasset, quod nec damnatum se esse diceret).

3 V. gr. D. 12.2.25 (Ulpianus libro 26 ad edictum. Sed et si servus meus delato vel relato ei iureiurando, iuravit rem domini esse vel ei dari oportere, puto dandam mihi actionem vel pacti exceptionem propter religionem et conventionem); D. 12.2.30.5 (Paulus libro 18 ad edictum): Si iuravero usum fructum mihi dari oportere, non aliter dari debet, quam si caveam boni viri arbitratu me usurum et finito usu fructu restituturum. 
entonces habrá lugar a la excepción. Parece muy clara, por tanto, la relación entre la denegación de la acción y la excepción del juramento si nos atañemos a este único texto.

En su comentario a esta fuente, AMIRANTE considera clara la relación entre la denegatio actionis y la exceptio. Cuando el contenido del juramento del demandado es "se dare non oportere", los efectos son, o bien la denegatio actionis para el actor, o bien la exceptio iurisiurandi para el demandado, y la utilización de un recurso procesal en preferencia del otro se basa en si subsiste la controversia sobre el hecho de la prestación del juramento, tal y como se dispone en este texto ${ }^{4}$. Hay que destacar que, para el citado autor, no cabe la distinción entre el juramento voluntario, necesario, extra-procesal e in iure, pues todos ellos producen los mismos efectos ${ }^{5}$.

Por su parte, sostiene METRO que la denegatio actionis es anterior a la exceptio; que, en algunos casos, la denegación ha sustituido a la exceptio, como en la fragmento comentado (D. 12.2.9 pr); que la exceptio se inserta en el curso de la evolución de la denegatio actionis; y que se trata de dar al juez la oportunidad de valorar una circunstancia que, examinada in iure, daría lugar a la denegatio actionis. En concreto, dice este autor, este paso es iluminante por cuanto que, cuando persiste controversia sobre el hecho del juramento, entonces se inserta una excepción: en otro caso, se deniega la acción. Aunque este autor no entiende que la relación entre la denegatio actionis y la exceptio se pueda plantear siempre en los mismos términos que en D. 12.2.9 pr, sin embargo, sostiene que ha habido una evolución, y que las fuentes sólo recogen el punto de llegada. Indica que es muy relevador el hecho de que en D. 44.5, sobre "quarum rerum actio non datur", se contemple, entre otras, la exceptio, cuyo origen se encuentra en una cláusula edictal concerniente a la denegatio actionis ${ }^{6}$.

Por su parte, BIONDI afirma que el juramento del demandado estaba garantizado por la denegatio actionis, y no por la exceptio, que, desde un punto de vista abstracto, aparece superflua, porque si se trataba de indagar an iuratum sit, y non an debetur, el propio Pretor podría llevarla a cabo por medio de la cognitio pretoria, y, por tanto, proceder a la denegatio actionis. Entiende que la referencia a la exceptio es una interpolación, en la medida en que en derecho justinianeo la denegatio actionis viene a menos, por lo que se concedía la exceptio iurisiurandi, que incluso debía de identificarse con la exceptio rei iudicatae ${ }^{7}$.

Para este autor, el juramento voluntario genera a favor del jurante una especial actio y exceptio iusiurandi, mientras que el juramento necesario está garantizado mediante una denegatio actionis o la concesión de la actio iudicati en el caso de que haya sido el demandante el que haya jurado $^{8}$. Si bien estamos de acuerdo con las conclusiones de esta autor, pondremos de manifiesto en este artículo los motivos para sostenerlas.

Por su parte, sobre la posibilidad de denegar la acción al demandante, DE CASTROCAMERO señala que el juramento debía prestarse entre la in ius vocatio y la datio actionis, puesto que "si el pretor hubiera concedido la acción, no sería adecuado que después la denegara" (sic). En todo caso, la denegatio no evitaba que el demandante ejercitase de nuevo la

4 L. AMIRANTE, Il giuramento prestato prima della litis contestatio nelle legis actiones e nelle formulae, Nápoles, 1954, pp. 66-67.

5 L. AMIRANTE, Il giuramento prestato prima della litis contestatio nelle legis actiones e nelle formulae, cit., p. VIII, adelanta en la introducción lo que será la conclusión de su estudio.

6 A. METRO, La denegatio actionis, Milán, 1972, pp. 80 y ss.

7 B. BIONDI, Il giuramento decisorio nel processo civile romano, Roma 1970, p. 31,n.4; p. 68.

8 B. BIONDI, Il giuramento decisorio nel processo civile romano, cit., p. 41. 
acción, por lo que es insuficiente para proteger al demandado que ha prestado el juramento. De ahí que el pretor haya comenzado a utilizar una exceptio (D. 12.2.9)9.

Nosotros no entendemos acertada la razón por la que esta autora indica que el juramento debió de haberse prestado entre la in ius vocatio y la datio actionis: no es que no sea adecuado (sic) que denegase la acción después de concedida, sino que sería imposible y, además, se habría producido los efectos inherentes a la litis contestatio, efectos de los que participa también el juramento. Como se ve, el contenido del juramento y su momento de prestación determinan los efectos del mismo y su régimen jurídico: no cabe reiterar la acción cuando el juramento es necesario puesto que coincide con la pretensión procesal, mientras que el Pretor debe conceder una excepción si se ha jurado una cuestión distinta de la pretensión ${ }^{10}$.

Por lo tanto, mientras que AMIRANTE sostiene que los efectos del juramento dependen de si ha jurado el demandante o el demandado, para BIONDI sus efectos dependen de si el juramento es necesario o voluntario, produciendo el efecto de la denegatio actionis en caso del juramento necesario, o bien la denegatio, o una exceptio en caso del juramento voluntario. Para DE CASTRO-CAMERO, sin embargo, habría que combinarse ambas vías procesales para proteger el juramento prestado por el demandado.

$\mathrm{Si}$, como sostenemos, es necesario el juramento cuyo contenido coincide con la intentio o la nominatio facti de la fórmula, entonces los efectos del juramento se derivan del contenido del juramento y, por tanto, del hecho de que se trate o no de un juramento necesario. De ahí la importancia del criterio de distinción que se basa, precisamente, en los efectos jurídicos del juramento, y que se desprenden de los textos que veremos a continuación, esclareciendo la relación entre denegatio actionis/exceptio iure iurando referida en D. 12.2.9 pr.

Debemos citar el párrafo D. 12.2.9.1, que parece contradecir el texto anterior.

\footnotetext{
(Ulpianus libro 22 ad edictum): Iureiurando dato vel remisso reus quidem adquirit exceptionem sibi aliisque, actor vero actionem adquirit, in qua hoc solum quaeritur, an iuraverit dari sibi oportere vel, cum iurare paratus esset, iusiurandum ei remissum sit.
}

De acuerdo con este fragmento, el juramento prestado o remitido al demandado produce una excepción para sí y para otros. Por su parte, el actor adquiere una acción, en la cual se pregunta sólo si se juró “dari sibi oportere", o si se remitió el juramento ante la disposición del demandado a jurar.

Esta fuente no lleva a cabo la misma distinción que el texto D. 12.2.9 pr cuando el demandado presta el juramento, sino que éste adquiere una excepción sin una ulterior precisión. Así, los efectos que produce el juramento dependen de quien presta el juramento, de tal manera que si el demandado presta el juramento, tendrá una excepción y, si lo presta el demandante, tendrá una acción.

Por tanto, los efectos del juramento necesario dependen, según este texto, de quién haya jurado, y no de que subsista la duda de si el demandado juró a fin de denegar la acción o conceder

9 R. DE CASTRO-CAMERO, Soluciones in iure a una controversia patrimonial: transacción, juramento y confesión, Sevilla, 2006, p. 179. Nos sorprende esta opinión en la medida en que el D. 12.2.9 es claro en este sentido: cuando subsiste controversia por la prestación del juramento, se concede una excepción. En otro caso, se deniega la acción.

${ }^{10}$ Los textos que equiparan la prestación del juramento a la cosa juzgada son, entre otros, el D. 12.2.30.3 (consunción por juramento de la acción pública); D. 12.2.9.3 (efecto de la perpetuidad de la obligación que también se produce con la prestación del juramento); D. 12.2.42.3 (el fiador será protegido cuando el deudor jura, porque la cosa juzgada aprovechará a ambos); D. 44.5.1 (dice expresamente que el juramento tiene el efecto de la cosa juzgada). 
una excepción. Por ello, debemos analizar otras fuentes con el fin de discernir si el efecto del juramento necesario prestado por el demandado es la denegatio actionis o una exceptio.

\begin{abstract}
D. 12.2.28.4 (Paulus libro 18 ad edictum): Exceptio iurisiurandi non tantum si ea actione quis utatur, cuius nomine exegit iusiurandum, opponi debet, sed etiam si alia, si modo eadem quaestio in hoc iudicium deducatur, forte si ob actionem mandati negotiorum gestorum societatis ceterasque similes iusiurandum exactum sit, deinde ex isdem causis certum condicatur, quia per alteram actionem altera quoque consumitur.
\end{abstract}

El supuesto es el siguiente: la excepción de juramento debe oponerse no sólo si se trata del mismo juicio, sino también en el caso de que sea llevada la misma cuestión a otro juicio. Por ejemplo, si se prestó juramento en una acción de mandato, de gestión de negocios, de societas o de otras similares, se extingue también la condictio que se intenta por la misma causa. La consunción de la que habla el texto es una consunción ope exceptionis.

El juramento prestado en las acciones nacidas de un contrato de buena fe no es un juramento necesario, sino un juramento voluntario: no cabe que se jure la pretensión porque ésta es incierta. El juramento necesario sólo cabe cuando se ejercita una acción con intentio certa, pues de otro modo el juramento no podía ser un medio de finalización del litigio, ya que las partes desconocen la pretensión, la petición principal, que será valorada por el juez ex fide bona tras la práctica de la prueba.

Por consiguiente, en las acciones de buena fe, como se ha dicho, y dado que la intentio es incierta, no se puede ofrecer el juramento decisorio, pues la pretensión es, en sí misma, indeterminada, y habría que reproducir el mismo juicio para determinar la pretensión. El proceso no puede finalizar por el juramento de deber o no deber "quidquid ob eam causam", sino que el quantum debe estar determinado y ser cierto para que se pueda prestar el juramento necesario. Entonces, en este tipo de juicios el juramento es siempre voluntario. Y cuando se presta el juramento voluntario o por una cuestión de hecho, el efecto es, como indica este texto, una excepción.

Aunque refiriéndose al efecto de la excepción tras la prestación de un juramento, esta fuente deja abierta la relación entre la denegación de la acción y la excepción. Hemos de seguir analizando otros textos, en este caso distintos apartados de este mismo fragmento (D. 12.2.28).

D. 12.2.28.5 (Paulus libro 18 ad edictum): Si quis iuraverit se non rapuisse, non debet adiuvari hoc iureiurando in actione furti aut condictione, quia aliud est furtum fecisse, quod vel clam fieri potest.

Si alguien hubiese jurado que no ha habido rapina, no debe aprovecharse de este juramento en la acción de hurto o en la condicción, porque cometer hurto es una cosa distinta, que se puede hacer incluso ocultamente. Una cosa es la rapiña, que es un hurto cualificado por haberse cometido con violencia; y otra muy distinta es un hurto simple: el no haber robado con violencia no excluye el haber robado. En este caso, el objeto del juramento es claramente una cuestión de hecho, y su efecto es de una excepción procesal.

De nuevo, el efecto de un juramento cuyo contenido es diferente de la pretensión jurídica no es la denegación de la acción, sino la concesión de una excepción cuando se ha jurado que no ha habido rapina en la actio furti, o bien en la condictio furtiva.

Estos dos textos van delimitando mejor las consecuencias jurídicas del juramento necesario. A diferencia del primero de los textos citados, el criterio para la concesión de una excepción o la denegación de la acción es el contenido del juramento y no la subsistencia de la duda de si ha habido o no juramento.

Este criterio del contenido del juramento se aprecia también en los fragmentos siguientes. 
D. 12.2.28.6 (Paulus libro 18 ad edictum): Colonus, cum quo propter succisas forte arbores agebatur ex locato, si iuraverit se non succidisse, sive e lege duodecim tabularum de arboribus succisis sive e lege Aquilia damni iniuria sive interdicto quod vi aut clam postea convenietur, per exceptionem iurisiurandi defendi poterit.

Si el colono (el arrendatario) ha jurado que no ha talado los árboles en la actio ex locato, podrá defenderse por medio de la excepción de juramento cuando se ejercite la acción de tala de la Ley de las XII Tablas, la Ley Aquilia de daños injustos, o el interdicto "de lo que a violencia o clandestinamente".

En este apartado, la acción que se ejercita es la actio ex locato, en la que el demandado jura no haber talado los árboles. De nuevo, ante el ejercicio de una acción de buena fe, el juramento tiene por objeto una cuestión de hecho y su efecto es la concesión de una excepción, que aprovechará al demandado ante el ejercicio de acciones futuras.

Afirma AMIRANTE que, en este caso, la consunción de la acción se produce por la fuerza del juramento prestado, ya que no puede hablarse de concurrencia entre las acciones mencionadas ${ }^{11}$. En realidad, el fragmento sólo pone de manifiesto la concesión de una excepción para el caso de futuras acciones, y no el resultado de esas acciones futuras y, desde luego, se limita a subrayar que el juramento aprovechará en esas nuevas acciones, y no que estas acciones se consuman por la prestación de un juramento en la actio ex locato.

Como se dispone en este texto, el contenido del juramento es una cuestión de hecho ("se non succidisse") y, como cuestión de hecho objeto de un juramento, pasará a los juicios posteriores como un hecho probado y, por tanto, será valorado por el juez por medio de su introducción en la fórmula como una excepción.

BIONDI sostiene que es natural que Paulo entienda que ha de concederse la exceptio iusiurandi en vez de la exceptio re iudicatae en este caso, puesto que se trata de un juramento voluntario que presta el actor a falta de otros medios de prueba ${ }^{12}$. Debemos decir que estamos por completo de acuerdo con este autor, porque el contenido del juramento es una cuestión de hecho, se trata de un juramento voluntario y, en consecuencia, no se decide, a su través, el juicio.

Una vez más, las fuentes ponen de relieve que, si el efecto es una excepción, se debe a que se trata de un juramento sobre un hecho, y no sobre la propia pretensión jurídica. Así, se jura "se non succidisse", esto es, si no ha talado los árboles. Por tanto, ese hecho jurado pasa a resultar probado en todas las acciones que pudiesen derivar de la tala de árboles.

D. 12.2.28.7 (Paulus libro 18 ad edictum): Quae iuravit divortii causa rem se non
amovisse, non debet defendi per exceptionem, si cum ea in rem agatur, et si contendat
suam esse, alio iureiurando opus est: contra si iuraverit suam esse, debet in actione
rerum amotarum defendi. Et omnino hoc observandum est, licet per aliam actionem
eadem quaestio moveatur, ut exceptio iurisiurandi locum habeat.

En esta fuente, si la mujer jura que no ha robado cosas de su marido con ocasión del divorcio, no quedará protegida por la excepción del juramento cuando se ejercita contra ella la

${ }^{11}$ L. AMIRANTE, Il giuramento prestato prima della litis contestatio nelle legis actiones e nelle formulae, cit., p. 123.

12 B. BIONDI, Il giuramento decisorio nel processo civile romano, cit., pp. 81-82. L. AMIRANTE, Il giuramento prestato prima della litis contestatio nelle legis actiones e nelle formulae, cit., n.142, pp. 89-90, objeta a la tesis de BIONDI que no puede tratarse de un juramento in iudicio, pues en ese caso se concedería la exceptio rei iudicatae y, aunque admite (como nosotros) que pudiera ser que no cupiese la exceptio rei iudicatae debido a que no subsiste eadam res, lo cierto es que del contexto se infiere que se trata de un juramento prestado ante litem contestatam, que se debe inferir del contexto textual. De nuevo, nos parece que antepone sus propias categorías a los hechos, y el hecho es que se trata de un juramento de hecho prestado en juicio que hace prueba del extremo jurado en otros juicios. Esta autor, sin embargo, prefiere decantarse por la opinión de que el juramento se prestaba antes de la litis contestatio, con el efecto de que se concedía una excepción en todas las acciones que se ejercitasen después, incluida la actio ex locato. 
actio reivindicatoria. Para que la mujer quede protegida por la excepción derivada del juramento cuando se ejercita la reivindicatoria, es necesario que jure que la cosa era suya. En ese caso (cuando jura que la cosa es suya), quedará defendida frente a la acción de cosas amovidas.

De acuerdo con AMIRANTE, en este texto aparece clarísima la importancia del juramento en materia de consunción, además del hecho de que un juramento divortii causa rem se non amovisse no excluye la rei vindicatio, pero que un juramento "rem suam causa" excluye la actio rerum amotarum ${ }^{13}$. En realidad, este texto pone de relieve que el contenido del juramento es lo más importante hasta el punto de que tal contenido determina sus efectos.

Para nosotros, el texto tiene el siguiente sentido: el juramento de no haber robado no puede paralizar la rei vindicatio, porque el objeto litigioso no es el mismo. En cambio, el juramento "rem suam esse" paraliza también la actio rerum amotarum, pues no cabe hurto sobre las cosas propias.

El juramento tiene la fuerza de fortalecer la afirmación jurada, y fortalecerla a todos los efectos jurídicos. Era, por así decirlo, la fórmula de solemnización para el proceso, equiparable, por ello, a la sentencia. Y es que, tal y como dice el D. 12.2.11.3, el juramento de hereditatem meam esset, equivale a si secundum me de hereditate pronuntiatum esset ${ }^{14}$.

Además del fragmento D. 12.28 en sus distintos apartados, la conclusión de que el juramento voluntario no produce el efecto de la denegatio actionis sino una excepción se infiere del siguiente pasaje.

D. 12.2.36 (Ulpianus libro 27 ad edictum): Ulpianus libro 27 ad edictum. Si actor deferat iusiurandum de sola constituta pecunia et reus iuraverit, exceptione utetur, si de constituta conveniatur: sed si de sorte, id est de priore obligatione conveniatur, exceptio cessabit, nisi de hac quoque iuraverit adversario deferente.

Si el actor difiere el juramento de haberse celebrado el negocio "pecunia constituta", y el demandado jura, podrá utilizar la excepción si se le demanda por la acción de pecunia constituta. Pero si se le demanda por la obligación constituida a plazo, cesa la excepción, a no ser que pida de nuevo un juramento en este nuevo juicio, cuyo contenido desconocemos. De nuevo, hemos de comentar lo mismo: el juramento sobre el hecho de la pecunia constituta, no paraliza la acción por el crédito principal.

A pesar de que en ningún otro texto se establece la relación entre la exceptio y la denegatio actionis como se lleva a cabo en D. 12.2.9.pr, sin embargo, las distintas fuentes que hemos ido analizando dan noticia de los supuestos en que se concedía la excepción derivada del hecho de jurar. Hemos verificado, así, que la excepción se daba cuando el contenido del juramento no coincidía con pretensión jurídica, de manera que, contrario sensu, no se procedía la excepción ante la juramento de la pretensión jurídica: en el caso de que se prestado el juramento con un contenido coincidente con la pretensión, entonces el Pretor denegaría la acción.

En este sentido, consideramos que no puede acogerse la distinción entre ambos medios procesales habida en D. 12.2.9. pr, porque es inexacta: las dudas que subsisten se deben a que no

${ }^{13}$ L. AMIRANTE, Il giuramento prestato prima della litis contestatio nelle legis actiones e nelle formulae, cit., p. 123.

${ }^{14}$ D. 12.2.11.3 (Ulpianus libro 22 ad edictum): Si, cum de hereditate inter me et te controversia esset, iuravero hereditatem meam esse, id consequi debeo, quod haberem, si secundum me de hereditate pronuntiatum esset. Et non solum eas res restituere debes, quas tunc possidebas, sed et si quas postea coepisses possidere, perindeque haberi quod iuratum est atque si probatum esset: idcirco utilis actio mihi competit, quod si ego ex eadem hereditate possiderem tuque coepisses petere eam a me, cum adversus te iurassem, exceptione me uti debere iurisiurandi. Plane si alius a me hereditatem petere coeperit, dubium non erit, ut et Iulianus scribit, nihil mihi iusiurandum prodesse. 
se ha decidido la cuestión principal por medio del juramento, de manera que el extremo jurado ha de ser valorado en un juicio ulterior con la introducción de una excepción en la fórmula.

En este punto, debemos considerar los siguientes fragmentos, que pueden poner, al menos en apariencia, en duda el efecto principal de denegar la acción cuando se presta el juramento necesario, que comentaremos brevemente: D. 12.2.26.1; D. 12.2.42.1, y D. 44.5.1.3.

D. 12.2.26.1 (Paulus libro 18 ad edictum): Si pater filium dare non oportere iuraverit, Cassius respondit et patri et filio dandam exceptionem iurisiurandi: si pater iuraverit in peculio nihil esse, filius conveniri poterit: sed et pater ita convenietur, ut post adquisiti peculii ratio habeatur.

Se trata de un juramento de derecho, en el que se jura la pretensión (“dare non oportere”). Ambos, padre e hijo, podrán oponer la excepción del juramento cuando el padre jura que el hijo no debe dar. Ahora bien, si el padre jura que no hay nada en el peculio (in peculio nihil esse), entonces se puede demandar al hijo, y al padre en las adquisiciones futuras para el peculio.

D. 12.2.42.1 (Pomponius libro 18 epistularum): Si fideiussor iuraverit se dare non oportere, exceptione iurisiurandi reus promittendi tutus est: atquin si, quasi omnino idem non fideiussisset, iuravit, non debet hoc iusiurandum reo promittendi prodesse.

Si el fiador jurase que no debe dar, el deudor principal podrá oponer la excepción de juramento. Pero si juró que no había prestado fianza, entonces no debe aprovecharle el juramento al deudor principal.

D. 44.5.1.3 (Ulpianus libro 76 ad edictum): Si fideiussor iuravit, si quidem de sua persona tantum iuravit, quasi se non esse obligatum, nihil reo proderit: si vero in rem iuravit, dabitur exceptio reo quoque.

Si el fiador juró "se non esse obligatum", pero sólo en cuanto a su persona, no aprovechará al reo. Si juró in rem, también se le dará al reo una excepción.

En estos tres supuestos, se jura la pretensión y, sin embargo, el efecto del juramento necesario no es la denegación de la acción, sino una excepción en una ulterior acción. A pesar de que, así enunciados, los textos pudieran comprometer nuestra conclusión, lo cierto es que en estas tres fuentes no se produce la triple identidad de persona, objeto y cosa en la acción sucesiva, sino que se ejercita la acción contra un tercero: sea el hijo, o el deudor principal.

Por tanto, el juramento necesario, cuyo contenido coincide con la intentio de la fórmula, produce el efecto de la denegación de la acción cuando se verifica la triple identidad de la cosa juzgada. En otro caso, producirá tan sólo un excepción, al igual que en el caso del juramento voluntario. 


\section{JURAMENTO PRESTADO POR EL DEMANDANTE: ACTIO EX IURE IU- RANDO}

Cuando el demandante presta el juramento necesario y, por tanto, jura "dare mihi oportere" $" 15$ en las acciones personales, o bien "rem suum esse" 16 en las acciones reales, el Pretor le concede una acción por el hecho del juramento ante el incumplimiento del condenado: actio ex iure iurando. Sin embargo, la fórmula de la acción, aunque reconstruida por algunos autores, es muy discutida.

De hecho, LENEL intenta solamente la reconstrucción de la intentio de la fórmula y advierte que no garantiza que los términos sean exactos. Así, propone dos intentio, dependiendo de si el juramento fue o no remitido por el demandado: S. p. Am Am NoNo sibi sestertium decem milia dare oportere; S.p. Nm Nm Ao Ao, cum is illo deferente paratus esse, iurare illum sibi decem milia dare oportere, iusiurandum remisisse... (sic). Añade que, cuando se haya prestado el juramento en las acciones de buena fe, se añadirá a la acción inicial una demonstratio «quod As As ...iuravit se depossuisse $\gg^{17}$. Por tanto, para LENEL, el juez debía comprobar que se hubiese prestado el juramento o que se hubiese remitido éste cuando el demandante hubiese estado dispuesto a jurar. En otro orden de cosas, como ya hemos indicado, sólo cabía el juramento necesario en acciones con intentio certa, de manera que no cabe plantear la fórmula de la acción que se derivase de un juramento prestado en acciones de buena fe, como también hace LENEL, equivocadamente, a nuestro entender.

Destacan VALIÑO y D’ORS las dificultades de LENEL para reconstruir la fórmula de esta acción, por lo que, como precaución metodológica, se debe abandonar la idea de que la actio ex iureiurando era una acción amoldada a la acción básica. Señalan que la actio ex iureiurando era una acción personal, in factum conceptae, tal y como se deduce de CJ 4.1.8 ${ }^{18}$, y que tenía por causa el juramento mismo o la estimación, en su caso, a los efectos de condena. Deben a AMIRANTE la mencionada precaución metodológica de distinguir los supuestos en los que el recurso procesal derivado del juramento se amolda a la acción básica o da lugar a una acción nueva, que es la actio ex iureiurando ${ }^{19}$.

En efecto, AMIRANTE distingue tres supuestos derivados de la prestación del juramento por el demandante, que este autor denomina "juramento positivo", porque su formulación es afirmativa: se afirma la existencia de un derecho. Los tres supuestos son: juramento "dare sibi oportere", del que se deriva una acción en la que únicamente se discute si se prestó el juramento; juramento "vendidisse me ei rem, societas fecisse, pignori dedisse fundum, rem in dotem dedisse", de las que no deriva ninguna acción especial, sino que la fórmula de la acción contractual

${ }^{15}$ V. gr. D. 12.2.9.1 (Ulpianus libro 22 ad edictum) Iureiurando dato vel remisso reus quidem adquirit exceptionem sibi aliisque, actor vero actionem adquirit, in qua hoc solum quaeritur, an iuraverit dari sibi oportere vel, cum iurare paratus esset, iusiurandum ei remissum sit; y D. 12.2.9.6 (Ulpianus libro 22 ad edictum) Iusiurandum defensoris vel procuratoris ei ab adversario delatum prodesse exceptionemque domino parere Iulianus scribit. Idem ergo dicendum erit et si datus ad petendum procurator reo deferente iuraverit dari mihi oportere: nam actionem mihi parit. Quae sententia habet rationem.

${ }^{16}$ V. gr. D. 12.2.25 (Ulpianus libro 26 ad edictum): Sed et si servus meus delato vel relato ei iureiurando, iuravit rem domini esse vel ei dari oportere, puto dandam mihi actionem vel pacti exceptionem propter religionem et conventionem.

17 O. LENEL, Essai de reconstitution de l'Èdit perpétuel,I, París, 1901, pp. 168 y ss.

18 CJ. 4.1.8: Imperatores Diocletianus, Maximianus. Actori delato vel relato iureiurando, si iuraverit vel ei remissum fuerit sacramentum, ad similitudinem iudicati in factum actio competit. De acuerdo con este texto, Ofrecido o referido el juramento por el actor, si se juró o si fue remitido el juramento, le compete una acción in factum similar a la actio iudicati.

${ }^{19}$ E. VALIÑO DEL RÍO y Á. D’ORS, El problema de la «actio ex iureiurando», en Estudios de derecho romano: homenaje al profesor Don Carlos Sanchez del Rio y Peguero, Zaragoza, 1967, pp. 183-184. 
se adapta para evitar que el juez exija la prueba de lo jurado; juramento "rem suam esse, hereditatem meam esse, usufructum meum esse", en el que se ejercita la propia acción real. En cuanto a la actio ex iureiurando, que se concede solamente en el primero de los supuestos, este autor considera que la acción sería una actio in factum, en la que no se discute el dare oportere, sino sólo la prestación o remisión del juramento, tal y como se deduce de I 4.6.11 y CJ 4.1.8, de cuya clasicidad no tiene duda alguna. En CJ 4.1.8 se habla de un acción ad similitudinem iudicati, aunque las diferencias entre la actio iudicati y la actio ex iureiurando serían no poco significativas: en la actio iudicati, se presupone siempre una condena pecuniaria, mientras que la actio ex iureiurando puede ejercitarse tras un juramento sobre rem dari sibi oportere; la actio iudicati crece al duplo en caso de infitatio, y la actio ex iureirando es una acción por el simple; no hace falta esperar para ejercitar la actio ex iureiurando los dies iusti, a diferencia de lo que sucede con la actio iudicati. La similitud, por tanto, proclamada en CJ.4.1.8 se reduce a que, tanto en un caso como en el otro, no se puede discutir ni el iudicatum ni el iusiurandum ${ }^{20}$.

No podemos dejar de estar de acuerdo en esta distinción del juramento, porque se basa en su contenido. Sin embargo, este autor rechaza la distinción entre juramento voluntario y necesario tal y como lo ha llevado a cabo la doctrina, pero no aporta ningún criterio de distinción entre ambos juramentos que, sin embargo, no producen los mismos efectos.

Por otro lado, no podemos coincidir ni con la segunda ni con la tercera diferenciaciones. En cuanto a la segunda diferenciación relativa a los juramentos sobre la existencia de contratos, en realidad, este juramento puede ser un mero requisito de procedibilidad de la acción contractual que exigía el Pretor; o bien una diligencia preliminar ${ }^{21}$ con el fin de asegurarse de la acción que debe conceder o de la legitimación pasiva.

En cuanto al juramento necesario prestado en las acciones reales, el tercer supuesto del autor, no es posible, como dice AMIRANTE, que la acción que se ejercite sea la propia acción real, pues ese efecto supone no haber prestado juramento. Por el contrario, parece más acorde con la naturaleza decisoria del contenido del juramento que la actio ex iureiurando esté dirigida a determinar la condena pecuniaria, en el supuesto de que el demandado no haya devuelto la cosa, tal y como sostienen VALIÑO y D'ORS.

Por último, BERTOLINI indica que los efectos del juramento son un actio in factum ex iureiurando a favor del actor, que también aparece como acción útil en los textos. En todo caso, se trata de una acción de derecho pretorio, puesto que no aparece en las fuentes ninguna acción de derecho civil que se corresponda con la actio ex iureiurando ${ }^{22}$.

En consecuencia, para este autor no obsta el hecho de que algunos textos se refieran a esta acción derivada del juramento necesario como una acción útil (D. 12.2.29; D. 12.2.11.3; D. 12.2.13.5), fragmentos que analizaremos más adelante.

Los pasajes que citaremos a continuación, aunque no pertenezcan al Digesto, sino a las Instituciones y al Código de Justiniano, sin embargo, han sido citados los autores mencionados, que los consideran clásicos por su contenido: I. 4.6.11; y CJ. 4.1.8.

\footnotetext{
${ }^{20}$ L. AMIRANTE, Il giuramento prestato prima della litis contestatio nelle legis actiones e nelle formulae, cit., pp. 132 y ss; y pp. 71-72, por este orden.

21 Artículos 256 y ss de la Ley 1/2000, de 7 de enero, de Enjuiciamiento Civil.

22 C. BERTOLINI, Il giuramento nel diritto privato romano, en Studia Juridica XIII, Roma, 1967, pp 122 y ss. Dice que se justifica que se dé una acción de derecho pretorio en la medida en que el juramento tiene una carácter contractual; y que se excluye la posibilidad de perjurio.
} 
I.4.6.11: Item si quis postulante adversario iuraverit deberi sibi pecuniam quam peteret, neque ei solvatur, iustissime accommodat ei talem actionem, per quam non illud quaeritur, an ei pecunia debeatur, sed an iuraverit.

De acuerdo con este párrafo, si, pidiendo el juramento el adversario, el actor jura que se le debe el dinero que pide y no se le ha pagado, es muy justo que le dé la acción por la cual no se pide la pecunia debida, sino lo que ha jurado.

No cabe ninguna duda de que el contenido del juramento es la pretensión jurídica "dare sibi pecuniam", pero el objeto de la acción derivada del juramento es el propio juramento, y no la deuda pecuniaria. Pero tampoco puede desconocerse que el contenido del juramento es la propia deuda, que pasaría a incontrovertida en la acción derivada del juramento: el juramento convierte en abstracta la obligación anterior.

CJ 4.1.8: Imperatores Diocletianus, Maximianus. Actori delato vel relato iureiurando, si iuraverit vel ei remissum fuerit sacramentum, ad similitudinem iudicati in factum actio competit.

De acuerdo con este texto, si el demandante juró o se le dispensó de jurar, bien por ofrecimiento del demandado bien por la devolución a jurar, le compete una acción in factum similar a la actio indicati.

Comenta este fragmento GLÜCK, que sostiene que la acción derivada del juramento es siempre una acción personal pretoria ${ }^{23}$. Por su parte, APPLETON considera que la acción que derivada del juramento sería una acción real, in factum: para este autor, sería la misma acción que el jurante pretendía ejercitar con una modificación en la fórmula, fórmula que propone: " $\mathrm{Si}$ paret Aulum Agerium, Numerio Negidio deferente, juravisse fundum Cornelianum suum esse ex iure quiritum, neque is fundus restituetur, quanti ea res erit, $\mathrm{Nm} \mathrm{Nm} A^{o} A^{o}$ condemna"24. Según esta reconstrucción, si resulta que Numerio Negidio ofreció el juramento a Aulo Agerio y éste juró que la cosa era suya por derecho civil, que Numedio Negido sea condenado a cuánto valdrá la cosa, si no la restituye.

Sin embargo, a pesar de lo que afirma el autor, la fórmula así propuesta no es real, sino personal, puesto que en la nominatio facti se mencionan tanto el demandante como el demandado, y sobre el hecho que deberá conocer el juez es si Aulio Agerio ha jurado previo ofrecimiento de Numedio Negidio. De hecho, al igual que sucede con la sentencia en los juicios reales, el juramento tiene un efecto relativo en las acciones reales, y el juez ha de asegurarse que el juramento haya sido ofrecido por el demandado, de acuerdo con D. 12.2.7 ${ }^{25}$ y D. 12.2.9.7 $7^{26} \mathrm{En}$ concreto, en este último texto se afirma que se dará acción solamente contra el que defirió el

23 Autor citado por L. AMIRANTE, Il giuramento prestato prima della litis contestatio nelle legis actiones e nelle formulae, cit., n. 215, p. 117.

${ }^{24}$ C. APPLETON, Histoire de la propiété prétorienne et de l'action publicienne, I, París, 1974, pp. 345 y ss. Este autor comienza el análisis de la cuestión con los textos D. 6.2.7.7; D. 12.2.9.7; D. 12.2.11; y D. 12.2.11.1 y, sin embargo, observa en primer lugar que si se juró que había comprado, le corresponderá la actio ex empto, y si juró que celebró un contrato de sociedad, le corresponderá una actio pro socio. Como se puede inferir, el análisis no tiene en absoluto en cuenta el contenido del juramento, pues, en los casos que el autor destaca, la afirmación de los contratos es jurada, pero el juramento no equivale a un medio de finalización del litigio, sino a una diligencia previa (arts. 256 y ss LEC).

25 D. 12.2.7 (Ulpianus libro 22 ad edictum): Ait praetor: "Eius rei, de qua iusiurandum delatum fuerit, neque in ipsum neque in eum ad quem ea res pertinet actionem dabo." Eius rei sic erit accipiendum, sive de tota re sive de parte sit iuratum: nam de eo quod iuratum est pollicetur se actionem non daturum neque in eum qui iuravit neque in eos qui in locum eius cui iusiurandum delatum est succedunt.

${ }^{26}$ D. 12.2.9.7 (Ulpianus libro 22 ad edictum): Si petitor iuravit possessore deferente rem suam esse, actori dabitur actio, sed hoc dumtaxat adversus eum qui iusiurandum detulit eosque qui in eius locum successerunt: ceterum adversus alium si velit praerogativa iurisiurandi uti, nihil ei proderit. 
juramento al actor y contra sus sucesores, lo que excluye que el juramento necesario prestado en un juicio real tengo efectos frente a terceros.

También lleva a cabo la reconstrucción de esta acción MARTÍN MINGUIJÓN, que distingue los supuestos en los que se presta el juramento, sea una acción pecuniaria, o una acción no pecuniaria. Sigue, en este punto, a D'ORS y VALIÑO cuando indican que la acción que se deriva del juramento prestado en una acción real servirá para establecer la cuantía de la condena.

Acción pecuniaria: Si paret Am Am $N^{o} N^{o}$ deferente iuravisse $\mathrm{Nm} N \mathrm{Nm}$ centum dari opor-

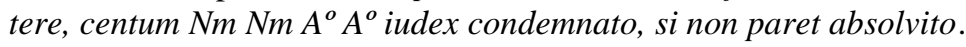

Acción no pecuniaria: Si paret Am Am $N^{o} N^{o}$ deferente iuravisse, quanti, era res est, tantae pecuniae iudex condemnato, si non paret absolvito ${ }^{27}$.

Entre ambas reconstrucciones, de APPLETON y de MARTÍN MINGUIJÓN, la reconstrucción de APPLETON reproduce, en la acción derivada del juramento, la misma acción real de base y, por tanto, con la posibilidad de devolver la cosa y evitar así la condena. Como ya expusimos, la reconstrucción como acción real de esta acción no es tal en la medida en que se mencionan tanto al demandante como al demandado en la nominatio facti.

Otra reconstrucción de la actio ex iureiurando la lleva a cabo MANTOVANI de esta manera:

\begin{abstract}
Actio (certae pecuniae) ex iureiurando dato. C. Aquilius iudex esto. Si paret A. Agerium N. Negidio condicionem deferente iurasse sibi sestertium X milia dare oportere, C. Aquilius iudex N. Negidium A. Agerio sestertium X milia condemnato; si non paret, absolvito.
\end{abstract}

Actio (certae pecuniae) ex iureiurando remisso. C. Aquilius iudex esto. Si paret N. Negidium A. Agerio, cum is illo condicionem deferente paratus essest iurare illum ei sestertium X milia dare oportere, iusiurandum remisse, C. Aquilius iudex N. Negidium A. Agerio sestertium X milia condemnato; si non paret, absolvito ${ }^{28}$.

Esta autor no ha reconstruido la acción derivada del juramento prestado en una acción real previa, sino que se ha centrado en la acción que deriva del juramento por el que se finaliza una acción personal. Así, reconstruye tanto la acción que deriva de una juramento efectivamente prestado, como la acción dimanante de la remisión del juramento.

Puede ayudarnos a discernir el carácter, personal o real, de la actio ex iureiurando, el agere per sponsionem. De acuerdo con GIOMARO, en Gayo, 4. $93^{29}$ las partes provocan una sponsio, una promesa, para reivindicar el bien, y de esta sponsio nace una acción in personam, aunque se indague si la cosa es de propiedad del demandante ${ }^{30}$. En el mismo sentido se manifiestan LOVATO, PULIATI y MARUOTI ${ }^{31}$.

Así, en caso de haber prestado el juramento necesario en una acción real también nacería una acción in personam, si bien con la diferencia de que, por medio del juramento necesario, se determina la propiedad del bien.

27 A.M. MARTÍN MINGUIJÓN, Fórmulas reconstruidas y acciones in factum conceptae, Madrid, 2001, p. 610.

${ }^{28}$ D. MANTOVANI, Le formule del processo privato romano, Padúa, 1999, pp. 69-70.

${ }^{29}$ Gayo, 4.93: Per sponsionem uero hoc modo agimus: prouocamus aduersarium tali sponsione: SI HOMO, QVO DE AGITVR, EX IVRE QVIRITIVM MEVS EST, SESTERTIOS XXV NVMMOS DARE SPONDES? deinde formulam edimus, qua intendimus sponsionis summam nobis dari oportere; qua formula ita demum uincimus, si probauerimus rem nostram esse.

30 A.M. GIOMARO, Agere per sponsionem: dal procedimento interdittale al procedimento in rem, en Studi urbinati di scienze giuridiche, politiche ed economiche (43),1990/91, pp. 205-206.

31 A. LOVATO. S. PULIATTI, L.SS. MARUOTI, Diritto Privato Romano, Turín, 2014, sostienen que, de hecho, se constituía un crédito por medio de una sponsio, en vez de ejercitar la legis actio per sacramentum. 
Hemos de considerar a continuación las fuentes del Digesto relativas a la acción derivada del juramento a fin de pronunciarnos acerca de la reconstrucción más fiel a la original.

D. 12.2.9.1 (Ulpianus libro 22 ad edictum): Iureiurando dato vel remisso reus quidem adquirit exceptionem sibi aliisque, actor vero actionem adquirit, in qua hoc solum quaeritur, an iuraverit dari sibi oportere vel, cum iurare paratus esset, iusiurandum ei remissum sit.

Según este texto, dado o remito el juramento, el demandado adquiere una excepción para sí o para otros, y el actor adquiere una verdadera acción, en la cual sólo se cuestiona si se ha jurado "dari sibi oportere", o si, estando dispuesto a jurar, se le remitió el juramento.

Este texto pone claramente el acento en el contenido del juramento: si y sólo si se juró "dari sibi oportere", el actor adquiere una verdadera acción en la que se discutirá únicamente el hecho de haber prestado o remitido el juramento. Al mismo tiempo, diferencia los efectos entre el juramento prestado por el actor y el demandado.

De acuerdo con este párrafo, la acción es una acción por el hecho del juramento y, por tanto, in factum. Se discute tan sólo que se haya prestado un juramento con el contenido "dari sibi oportere". Pero en esta acción no sólo se discute que haya prestado el juramento, sino que lo haya prestado por petición de la otra parte, tal y como dispone D. 12.2.9.7.

D. 12.2.9.7 (Ulpianus libro 22 ad edictum): Si petitor iuravit possessore deferente rem suam esse, actori dabitur actio, sed hoc dumtaxat adversus eum qui iusiurandum detulit eosque qui in eius locum successerunt: ceterum adversus alium si velit praerogativa iurisiurandi uti, nihil ei proderit,

El supuesto de este fragmento es el siguiente: el poseedor del bien reivindicado defirió el juramento al demandante, que juró que la cosa era suya. En este caso, se dará acción contra el que defirió el juramento o contra aquéllos que estén en su lugar, pero no podrá usar contra otros la prerrogativa del juramento.

En este caso, la limitación se incluye a propósito de una acción real, en la que se ha prestado el juramento necesario, puesto que las acciones reales se consumen ope exceptionis cuando no se produce la triple identidad de cosa, objeto y persona.

Sobre todo, nos interesa que la acción derivada del juramento se da contra el que ofreció el juramento o sus sucesores. Sobre este punto, insiste especialmente el texto D. 12.2.3.

\footnotetext{
(Ulpianus libro 22 ad edictum): pr. Ait praetor: "Si is cum quo agetur condicione delata iuraverit". Eum cum quo agetur accipere debemus ipsum reum. Nec frustra adicitur "condicione delata": nam si reus iuraverit nemine ei iusiurandum deferente, praetor id iusiurandum non tuebitur: sibi enim iuravit: alioquin facillimus quisque ad iusiurandum decurrens nemine sibi deferente iusiurandum oneribus actionum se liberabit.
}

Dice el Pretor: "si aquél contra el que se litiga ofrece el juramento". Por "eum", debe entenderse el reo. Por otro lado, remarca este fragmento la necesidad "condicione delata", esto es, se le debe ofrecer expresamente al demandado la posibilidad de jurar, porque si el demandado jura sin previo ofrecimiento, jura para sí, y no lo ampararía el Pretor: de otro modo, sería muy fácil deshacerse de los gravámenes de la acción si se jurase sin previo ofrecimiento de la parte contraria. Se remarca, de esta forma, la necesidad de que la posibilidad de jurar provenga de la parte contraria.

En consecuencia, la acción derivada del juramento debe darse por el hecho de que el demandante juró a iniciativa de la parte contraria, y no por propia voluntad. Por esta razón, las reconstrucciones de la fórmula de la actio ex iureiurando incluyen tanto al actor como al demandado en la nominatio facti de la acción. 
Nos resulta interesante el siguiente fragmento, en la medida en que hace referencia a la restitución en la actio ex iureriurando.

D. 12.2.11.1 (Ulpianus libro 22 ad edictum): Proinde si, cum possideret, deferente
petitore rem suam iuravit, consequenter dicemus amissa quoque possessione, si is qui
detulit iusiurandum nanctus sit possessionem, actionem in factum ei dandam. Et fruc-
tus perceptos ex re, quam meam esse iuravi, restitui mihi placuit: sed et partum
editum fetusque pecorum restituendos constat post iusiurandum delatum.

El supuesto de hecho de esta fuente es el siguiente: el demandado por una reivindicatoria (en principio, poseedor no propietario) jura que la cosa es suya. Luego, pierde la posesión a favor del demandante y se da contra el otrora demandante una acción por el hecho: esta acción obligará a restituir los frutos, incluso el hijo de la esclava y la cría de los animales. El demandado que ha jurado que la cosa es suya es protegido por una acción derivada del hecho de jurar, que obliga al demandante en la reivindicatio anterior a devolverle la cosa con sus frutos.

En este fragmento, por tanto, se menciona que una prestado el juramento, se dará acción a favor de quien juró que la cosa era suya cuando pierda la posesión, y esta acción conducirá no sólo a la restitución de la posesión, sino también a los frutos. Por tanto, será una restitución cum sua causa.

Esta fuente es única en lo que se refiere a la restitución de la cosa con sus frutos. LENEL no refiere interpolaciones en el texto ${ }^{32}$, de manera que hemos de considerarlo genuino y, en consecuencia, la actio ex iureiurando debe posibilitar la restitución de la posesión cum sua causa, tal y como destacó APPLETON en su reconstrucción.

Por otro lado, hay textos en los que se hace referencia a que la actio ex iureiurando como una acción útil, y por tanto, no se reconoce la existencia de una acción específica derivada del hecho de prestar el juramento. Como ya se dijo, los autores consideran que los textos que hablan de acciones útiles no obstan a la conclusión de que hay una actio in factum por el hecho del juramento.

Los textos que tratan la actio ex iureiurando como una acción útil son tres: D. 12.2.29; D. 12.2.11.3; D. 12.2.13.5.

D. 12.2.29 (Tryphoninus libro sexto disputationum): Quod si iuravi te deferente non iurasse te dare tibi oportere, et adversus utilem actionem, qua hoc quaeritur, an iuraveris tibi dari oportere, opponenda est exceptio iurisiurandi perementis quaestionem actione comprehensam.

Si, previa la iniciativa del demandante, el demandado jura que el demandante no juró "dare tibi oportere", esto es, que le debía dar, se ha de dar excepción al demandado en la acción útil por la que se comprueba que se ha prestado el juramento.

LENEL no hace una especial consideración a este texto, por lo que ha de tenerse por fiel al original ${ }^{33}$. Sin embargo, por lo rebuscado del supuesto, lo hemos de considerar más teórico que la resolución a un caso planteado, ya que, teniendo en cuenta que el juez debía decidir si el demandante había jurado que se le debía dar por iniciativa del demandado y no por su sola voluntad, parece más probable que el eventual juramento en la acción derivada del juramento sería si el demandado ofreció al demandante la posibilidad de jurar "dare tibi oportere", y no, como aparece en el texto, el hecho de que el demandante hubiese jurado.

\footnotetext{
32 O. LENEL, Palingenesia Iuris Civilis, II, Graz, 1960, p. 546.

33 O. LENEL, Palingenesia Iuris Civilis, II, cit., p. 358.
} 
D. 12.2.11.3 (Ulpianus libro 22 ad edictum): $\mathrm{Si}$, cum de hereditate inter me et te controversia esset, iuravero hereditatem meam esse, id consequi debeo, quod haberem, si secundum me de hereditate pronuntiatum esset. Et non solum eas res restituere debes, quas tunc possidebas, sed et si quas postea coepisses possidere, perindeque haberi quod iuratum est atque si probatum esset: idcirco utilis actio mihi competit, quod si ego ex eadem hereditate possiderem tuque coepisses petere eam a me, cum adversus te iurassem, exceptione me uti debere iurisiurandi. Plane si alius a me hereditatem petere coeperit, dubium non erit, ut et Iulianus scribit, nihil mihi iusiurandum prodesse.

Este paso de Ulpiano dice que, si hay controversia entre dos por una herencia, si uno jura que la herencia es suya (por tanto, contenido jurídico del juramento), entonces debe tener la herencia como si hubiese habido una sentencia favorable. Por tanto, deben ser restituidas no sólo todas las cosas que se poseían en el momento del litigio, sino también las que se empiecen a poseer después, y debe entenderse que lo jurado está como probado ("quod iuratum est atque si probatum esset”). El que así jura, tendrá la acción útil, así como la excepción de juramento contra quien ha jurado cuando le reclama la herencia. Pero no le aprovechará el juramento contra cualquier otro.

En realidad, en este texto no aparece un juramento necesario en la medida en que se jura que la herencia es suya, y no que se le debe dar la herencia. La actio ex testamento no es una acción real, sino una acción personal, un dare oportere: el heredero debe pedir la herencia como un crédito, in solidum. De acuerdo con LENEL, "c 'est que l'actio ex testamento avait une intentio basée sur un ex testamento dari oportere" ${ }^{34}$. En consecuencia, el juramento no es necesario, porque su contenido no coincide con la intentio de la actio ex testamento: se jura "hereditatem meam esse".

Para DE CASTRO-CAMERO, hay una contradicción entre el D. 12.2.11.2 $2^{35}$ y el D. 12.2.11.3. En este último fragmento, se daría una acción útil, que es una acción ficticia, mientras que en el primer texto (D. 12.2.11.2) sólo se habla de que el pretor dará una acción. Para la autora, las diferentes acciones derivadas del juramento de las que se habla en el D. 12.2.11 (D. 12.2.11.1: actio in factum; D. 12.2.11.2: se dará acción; D. 12.2.11.3: acción útil), se pueden explicar en el sentido de que, en todo caso, se trataría de acciones de naturaleza pretoria ${ }^{36}$.

En cuanto a nosotros, hemos de sostener que las diferencias varían en atención al contenido del propio juramento, de manera que del juramento necesario derivará una acción in factum personal.

D. 12.2.13.5 (Ulpianus libro 22 ad edictum): Marcellus etiam scribit, si quis iuraverit ob decem pignori dedisse fundum, non alias eum pigneraticia agere posse, quam si decem solverit: sed et illud adici fortassis eum etiam in decem ex iureiurando suo posse conveniri, quod magis probat. Cui quintus Saturninus consentit argumentoque utitur eius, qui iuravit eam, quae uxor sua fuerit, rem sibi in dotem dedisse: nam et hic uxori ait utilem de dote actionem dandam. Quae non esse extra aequitatem posita non negaverim.

Según este párrafo, Marcelo escribe que si alguien jura "ob decem pignori dedisse fundum", es decir, que ha dado prenda por la cantidad de diez, no podrá ejercitar la acción pirgnoraticia si no ha pagado los diez, de la misma manera que podrá ser demandado por el crédito de

${ }^{34}$ O. LENEL, Essai de reconstitution de l'Èdit perpétuel, I, cit., p. 274.

${ }^{35}$ D. 12.2.11.2 (Ulpianus libro 22 ad edictum): Item si iuravero usum fructum alicuius rei vel meum esse vel dari mihi oportere, eatenus mihi competit actio, quatenus, si vere usum fructum haberem, duraret: quibus vero casibus amitteretur, non competit mihi actio. Sed si rerum, in quibus usus fructus propter abusum constitui non potest, iuraverit usum fructum se habere vel sibi deberi, effectum iurisiurandi sequendum arbitror ideoque tunc quoque videri eum recte iurasse puto et ex eo iureiurando posse petere usum fructum cautione oblata.

${ }^{36}$ R. DE CASTRO-CAMERO, Soluciones in iure a una controversia patrimonial: transacción, juramento y confesión, cit., pp. 182 y ss. 
diez. Quinto Saturnino está de acuerdo, y pone el ejemplo de la mujer que jura que ha dado en dote una cosa, pues en este caso le corresponde a la mujer la acción útil de dote.

En este caso, la acción de dote puede ser útil para dejar fuera de la reclamación posterior de la dote un bien determinado, objeto del juramento, fingiendo que ese bien es de la mujer. En la medida en que la devolución de la dote estaba sujeta a la retenciones, podría darse una acción útil si la mujer jura que un bien forma parte de la dote. Pero este juramento no es necesario: no jura la pretensión de la fórmula de la actio rei uxoriae.

Como ya hemos comentado, autores como BERTOLINI no consideran que la existencia de estos textos obsten a la conclusión de la existencia de una actio ex iureiurando ${ }^{37}$. Pero tampoco tienen dudas al respecto los demás autores mencionados, como VALIÑO y D'ORS, que incluso titulan su trabajo con el nombre propio de la acción derivada del juramento ${ }^{38}$.

En todo caso, nosotros no tenemos dudas de que la actio ex iureiurando era una acción con entidad propia, por el hecho de que se haya prestado el juramento: hay más fuentes que hacen referencia a la existencia de una acción que se deriva del juramento que textos que indican que la acción que le corresponde al actor será útil: éstos últimos se reducen a los tres citados, de los cuales dos ni siquiera tratan del juramento necesario.

Indica D'ORS que las acciones in factum no pueden ser útiles porque no tienen intentio, pues las acciones útiles modifican las acciones civiles para alcanzar un determinada resultado, mientras que las acciones in factum están pensadas para conductas no contempladas en el derecho civil ${ }^{39}$. En el mismo sentido se expresa FERNÁNDEZ DE BUJÁN, quien señala que por medio de las acciones ficticias, el Pretor ordenaba al juez que finja que un requisito se ha cumplido en el ejercicio de las acciones civiles y, en cambio, las acciones in factum protegen un hecho no previsto por el ius civile $e^{40}$.

Solamente tres textos se refieren a la acción derivada del juramento como una acción útil, y ni siquiera todos estos textos recogen supuestos de juramento necesario, por lo que sí cabría una acción útil sobre la base de una primera acción que, por no prestarse el juramento necesario, no se ha consumido. Y ésta es la razón principal por la que no cabría una acción útil derivada del juramento necesario: la acción base se consume después de prestado el juramento necesario, y no es posible volver a ejercitarla como útil. Por ello, la acción que se deriva del juramento necesario debía ser una acción por el hecho del juramento.

Una vez descartada que la actio ex iureiurando pueda ser útil, hemos de pronunciarnos acerca de la reconstrucción de la fórmula que, en nuestra humilde opinión, resulta más acertada. En primer lugar, ha de hablarse de fórmulas, esto es, de una fórmula para la actio ex iureiurando derivada de una acción personal, y una fórmula derivada de una acción real.

En cuanto a la actio ex iureiurando por el hecho de un juramento prestado en una acción real, consideramos que la reconstrucción de APPLETON se ajusta más a las fuentes, toda vez que se contempla la posibilidad de que el demandado proceda a la devolución cum sua causa (D. 12.2.11.1).

En lo tocante a la acción por el juramento en una acción personal, consideramos que la reconstrucción de MANTOVANI acentúa más el hecho de que se debe probar que el juramento fue prestado "condicione deferente", tal y como se exige en D. 12.2.3, y que por ello se acerca

${ }^{37}$ C. BERTOLINI, Il giuramento nel diritto privato romano, cit., pp 122 y ss.

${ }^{38}$ E. VALIÑO DEL RÍO y Á. D’ORS, El problema de la «actio ex iureiurando», cit., pp. 181 y ss.

39 D’ORS, Derecho Privado Romano, 2004, Navarra, pp. 135 y ss.

40 A. FERNÁNDEZ DE BUJÁN, Derecho Privado Romano, Madrid, 2015, pp. 116-117. 
más a la acción que debió de otorgarse cuando el litigio finalizada por el juramento del demandante.

\section{CONCLUSIONES}

El Pretor protegía al beneficiado por el juramento necesario por medio de determinados recursos procesales: tales recursos eran los efectos del juramento necesario.

Estos recursos y, en consecuencia, los efectos del juramento necesario iban aparejados al contenido del propio juramento, que coincidía o bien con la intentio de las acciones in ius, o bien con la nominatio facti de las acciones in factum. Dada esta coincidencia, la acción base o la correspondiente a la relación jurídica entre las partes se consume y no podía volver a ejercitarse.

En consecuencia, el Pretor protegía al demandado por medio de la denegación de la acción al demandante, ante una eventual petición de acción. La denegación de la acción no se concedía siempre, sino que la acción ejercitada debía ser una acción personal y ser solicitada por la misma parte del litigio anterior.

Por el contrario, se debía conceder una excepción cuando no se producía la triple identidad de la cosa juzgada sobre la cosa, el objeto y la persona, pues en tales casos la acción no se habría consumido y la prestación el juramento habría de tomarse en consideración por medio de la introducción de una excepción en la fórmula. El juramento necesario genera una excepción no sólo en caso de una acción real en el que sea un tercero el que ejercite la acción (sin que verifique, en consecuencia, la triple identidad de la cosa juzgada), sino también en acciones personales cuando haya terceros fiadores o sucesores.

Cuando el demandante jura, que se le debe dar o que la cosa es suya, el Pretor le concede una acción in factum, personal, por el hecho del juramento, en el que sólo se discute la prestación del juramento a petición de la parte contraria en el caso de que el juramento haya tenido lugar en una acción personal previa. Por su parte, si el juramento se prestó en una acción real, esa acción personal in factum está dirigida a la estimación de la cosa, en el caso de que el demandado no la devuelva cum sua causa.

En definitiva, los efectos del juramento necesario se explican considerando el contenido de éste, que se erige, así, como el criterio más apropiado para la distinción entre el juramento necesario y voluntario.

Submetido em: 11 maio 2021.

Aceito em: 25 jun. 2021. 